\title{
A COOPERAÇÃO JURÍDICA INTERNACIONAL: O DIREITO INTERNACIONAL E OS MÉTODOS DE COOPERAÇÃO JURÍDICA À LUZ DO NOVO CÓDIGO DE PROCESSO CIVIL BRASILEIRO
}

\author{
INTERNATIONAL LEGAL COOPERATION: INTERNATIONAL LAW AND THE \\ METHODS OF LEGAL COOPERATION IN THE LIGHT OF THE NEW BRAZILIAN \\ CIVIL PROCEDURE CODE
}

Ana Carolina Pascolati ${ }^{1}$

Ana Luísa Moreli Pangoni²

\begin{abstract}
RESUMO: Este estudo apresenta como núcleo central uma análise acerca da importância dos mecanismos de cooperação jurídica internacional trazidos pelo Novo Código de Processo Civil Brasileiro, sobretudo o auxílio direto como meio de alcançar a cooperação internacional, em matéria cível. O estudo da cooperação internacional ressalta o chamado auxílio direto, como meio legal para comunicação de atos processuais, tais como intimação, citação e notificação, colheita de provas, obtenção de prestação de informações, além de medidas cautelares e decisões antecipadas na justiça brasileira. Com a possibilidade do procedimento do auxilio direto será possível ao Estado brasileiro solicitar a um Estado estrangeiro um ato jurisdicional que poderá ser entre órgãos judiciais, entre órgãos administrativos ou de um para o outro. O objetivo é analisar as hipóteses de atuação da autoridade brasileira fora dos limites do poder judiciário, autorizando o auxilio direto entre Estados estrangeiros. Em que pese aparecer timidamente no Novo Código de Processo Civil, a cooperação jurídica internacional significou importante avanço em matéria cível na análise de questões que envolvam autoridade brasileira e autoridades estrangeiras.
\end{abstract}

PALAVRAS CHAVE: Cooperação Jurídica Internacional. Direitos Humanos. Novo Código de Processo Civil.

\footnotetext{
${ }^{1}$ Professora de Direito Internacional do Damásio Educacional. Mestranda pela Pontifícia Universidade Católica de São Paulo (PUC/SP). Especialista Direito Constitucional e Internacional pela Universidade de Salamanca/Espanha. Especialista em Direito Público. Advogada do escritório Pascolati Advocacia. Diretora/Coordenadora da Unidade Damsio Santo Amaro. Endereço eletrônico: carolpascolati@gmail.com

2 Mestre em Direitos da Personalidade pela Unicesumar-PR. Especialista em Direito Processual Civil pela PUC-PR. Bacharel em Direito pela Universidade Estadual de Maringá-PR. Membro do grupo de pesquisa "Internacionalização do direito: dilemas constitucionais e internacionais contemporâneos" da Unicesumar-PR. Professora da Faculdade Alvorada em Maringá-PR. Advogada. Endereço eletrônico: analumoreli@hotmail.com.
}

http://revistasapereaude.org/index.php/edicoes/ano-5-volume-4-novembro-2016

D.O.I: 10.20523/sapereaude-ano5-vol-4-pg-19-39 
ABSTRACT: This research presents an analysis about the importance of the mechanisms of international legal cooperation brought by the New Brazilian Civil Procedure Code, specially the direct assistance as an action to reach the international cooperation in civil matters. The study of international legal cooperation highlight the direct assistance, as a legal action to the communication of procedure acts, such as legal notification, demand intimation, the evidence collection, to obtain information, besides precautionary measures and early decisions on Brazilian justice. The possibility of the use of direct assistance, it will be possible Brazilian State to request to a foreign State an jurisdictional act to a judicial sector or to an administrative sector, or to both of them. The aim is to analyses the hypotheses that Brazilian authority is able to act outside the limits of it's own judicial power, by authorizing the direct assistance between foreign States. Although the international legal cooperation has been timidly regulated at the New Brazilian Civil Procedure Code, the institute meant an important improvement in civil matters, specially in the analyses of questions that involve Brazilian authority and foreign authorities.

KEY WORDS: International Legal Cooperation. Human Rights. New Brazilian Civil Procedure Code.

\section{INTRODUÇÃO}

Com o fenômeno da globalização, o mundo vivencia a crescente circulação de pessoas, bens e serviços. Em razão disso, os Estados passaram a manter relações entre si, nas quais necessitam de auxílio entre eles para o exercício da prestação jurisdicional mais célere e efetiva. Isso porque, esses contatos fronteiriços

ajudou a fomentar a cooperação jurídica internacional que vem se desenvolvendo nos dias atuais.

O intercâmbio de pessoas, bens e serviços teve reflexos nos ordenamentos jurídicos, forçando-os a se adequarem às novas realidades, como ocorreu recentemente com o Novo Código de Processo Civil Brasileiro (NCPC). Como os fatos sociais são multiconectados ou plurilocalizados, eles podem ser regulados por mais de um ordenamento jurídico. Por esta razão, cabe ao Direito Internacional Privado (DIPr) regular essa potencialidade de aplicação espacial.

Ainda sob a perspectiva da globalização, o DIPr vem experimentando a influência das fontes internacionais, deixando de predominar as regras nacionais e limitadas ao território de determinado Estado. Como resultado, destaca-se uma 
tentativa de universalização da matéria por meio da elaboração de diversos tratados ou da cooperação, utilizando-se o princípio da reciprocidade entre os Estados.

A cooperação jurídica internacional estuda uma forma de solução para os conflitos de leis no espaço, e analisa os elementos de estraneidade. Sem dúvida, é um importante instituto do DIPr, pois visa à colaboração entre Estados soberanos em solicitar aos demais Estados a aplicação do seu direito em casos que envolvam conduta fora dos limites do seu território para facilitar o acesso a justiça.

\section{A COOPERAÇÃO JURÍDICA INTERNACIONAL}

Não se pode ao certo precisar quando e onde teve origem a cooperação jurídica internacional, o que se pode observar, neste contexto, é que o aumento do intercâmbio de pessoas, de bens e de serviços exigiu dos Estados uma cooperação mútua para assegurar o pleno acesso à justiça. Com isso, cooperar é mais do que um favor, é uma necessidade que a comunidade internacional enfrenta.

$\mathrm{Na}$ era dos direitos humanos, o DIPr, estudado e debatido nos encontros e convenções internacionais, é reconhecido como a matéria necessária para uma análise da teoria geral da cooperação jurídica internacional a fim de se promover o acesso à justiça universal nos dias atuais.

Nesse sentido, Nádia de Araújo explica que, num sentido amplo, cooperação jurídica internacional significa "o intercâmbio internacional para o cumprimento extraterritorial de medidas processuais provenientes do Judiciário de um Estado estrangeiro"3.

A estrutura básica da cooperação jurídica se molda nos seguintes elementos: sujeitos, vias de comunicação, pedido e veículo de transmissão do pedido. Os sujeitos podem ser os próprios Estados ou aqueles que se beneficiarão ou não da cooperação; as vias de comunicação podem ser por via diplomática, pela via da autoridade central, via contato direto ou até mesmo de maneira simples, via postal.

\footnotetext{
${ }^{3}$ ARAUJO, Nádia de. Direito Internacional Privado: Teoria e Prática Brasileira. Porto Alegre: Revolução eBook, 2016, p. 149.
}

http://revistasapereaude.org/index.php/edicoes/ano-5-volume-4-novembro-2016 
A tendência é cada vez mais se intensificar e se efetivar a cooperação jurídica no plano internacional, pois o contato de pessoas com outros Estados que não seja o seu se multiplica e a necessidade de normas internacionais de cooperação aumenta da mesma forma.

Nádia de Araújo ressalta que existem duas perspectivas sobre a concretização da cooperação jurídica que devem ser levadas em consideração:

[...] de um lado, uma perspectiva ex parte principis, ou seja, a lógica do Estado preocupado com a governabilidade e com a manutenção de suas relações internacionais; de outro, a perspectiva ex parte populi, a dos que estão submetidos ao poder, e cuja preocupação é a liberdade, à luz dos direitos humanos constitucionalmente protegidos $^{4}$.

Em função do novo quadro de globalização e internacionalização, o Estado brasileiro reconheceu uma necessidade de regulamentar o tema, que era anteriormente regido pela Resolução n. 9/2005 e depois pelo Regimento Interno do STJ. Em 2016, com a entrada em vigor do Novo Código de Processo Civil, a matéria alcançou o status de lei, trazendo maior segurança jurídica.

Esta regulamentação, além de construir bases sólidas para a cooperação jurídica e o auxilio direto em matéria de direito civil, teve o intuito de se positivar aquilo que já se estava sendo utilizado pelo ordenamento jurídico e também pelo Poder Executivo, como, por exemplo, a chamada "Autoridade central".

O Brasil sempre se mostrou apto a ajudar os Estados soberanos no auxilio da cooperação, como Estado Requerente, mas seu auxílio como Estado Requerido era menor. Com a entrada em vigor do NCPC, é bastante perceptível a mudança estrutural tanto no ordenamento jurídico, quanto na prática dos Tribunais pátrios.

A lei brasileira não nega a existência de processo perante órgãos jurisdicionais estrangeiros envolvendo as mesmas partes, com o mesmo pedido e

\footnotetext{
${ }^{4}$ ARAUJO, Nádia de. Direito Internacional Privado: Teoria e Prática Brasileira. Porto Alegre: Revolução eBook, 2016, p. 150.
} 
mesma causa de pedir. A litispendência e/ou a coisa julgada, nestes casos, pressupõe a homologação da decisão estrangeira para surtir no Brasil seus efeitos.

O reconhecimento e a execução de sentença estrangeira tem significados diferentes. O reconhecimento implica em aceitação, ao passo que a execução será a consequência do pedido ao juiz, possuindo efeitos de uma sentença judicial com possibilidade a extensão no foro.

No que se refere ao auxílio direto, não se verificam muitos avanços com o NCPC, tendo em vista que este mecanismo já constava no manual do Ministério da Justiça e o Brasil já o adotava quando possível. Atualmente, ao adquirir o status de lei, admite-se a citação por este mecanismo, que pode ser feita sob a legislação processual brasileira quanto aos atos processuais em direito admitido.

Nesse sentido, antes de adentrar à regulamentação da cooperação, necessário se faz uma análise dos limites da jurisdição nacional e da cooperação jurídica internacional, como disposto nos artigos 21 a 25 do NCPC.

\subsection{OS MÉTODOS DE COOPERAÇÃO}

Os sistemas de recepção de atos jurisdicionais variam de um ordenamento jurídico para o outro e não há nenhum Estado que admita a execução direta de sentenças estrangeiras ${ }^{5}$.

A Doutrina comenta tipos de sistemas de atos jurisdicionais estrangeiros: 1) actio judicati (common law); 2) Exequatur - por vontade do Estado ou por delibação quando existe a análise de requisitos ${ }^{6}$.

\footnotetext{
${ }^{5}$ SOARES, Boni de Moraes. "Um réquiem ao velho juízo de delibação: homenagem póstuma à tradicional cognição no direito processual internacional brasileiro" in CARVALHO RAMOS, André de e MENEZES, Wagner. Direito Internacional Privado e a nova cooperação jurídica internacional. Belo Horizonte: Fórum, 2014, p. 57.

${ }^{6}$ SOARES, Boni de Moraes. "Um réquiem ao velho juízo de delibação: homenagem póstuma à tradicional cognição no direito processual internacional brasileiro" in CARVALHO RAMOS, André de e MENEZES, Wagner. Direito Internacional Privado e a nova cooperação jurídica internacional. Belo Horizonte: Fórum, 2014, p. 58.
}

http://revistasapereaude.org/index.php/edicoes/ano-5-volume-4-novembro-2016

D.O.I: 10.20523/sapereaude-ano5-vol-4-pg-19-39 
O juízo de delibação é o mais utilizado na produção de efeitos jurídicos e nada mais é do que - o modo de cognição de um dos sistemas de reconhecimento de atos jurisdicionais estrangeiros (sistema exequatur).

O sistema de Exequatur por delibação "toca de leve em seus requisitos externos, examinando sua legitimidade, sem entrar no mérito". Um dos elementos que compõem o juízo de delibação gira em torno da preservação dos princípios gerais do ordenamento jurídico do país ${ }^{7}$.

No Processo Civil Internacional Brasileiro é feita a análise dos requisitos formais (pressupostos processuais - art. 963 do NCPC e os requisitos materiais - art. 17 da LINDB).

A cooperação jurídica depende de mecanismos para se efetivar, sendo eles: carta rogatória, homologação e o mais novo deles (para o ordenamento jurídico brasileiro), o auxilio direto 8 .

A carta rogatória e a homologação diferenciam-se do auxilio direto pelo fato de serem instrumentos da cooperação que dependam do juízo de delibação do Estado requerido. A diferença entre os institutos está basicamente em seu conteúdo, sendo que a carta rogatória carrega em seu bojo uma decisão interlocutória, de caráter não definitivo, ao passo que a homologação traz em si um ato jurisdicional não sujeito a recurso que encerra definitivamente ao litígio, dependendo apenas da sua execução.

Os elementos da delibação podem ser descritos como: competência internacional do juízo, observação do contraditório, ausência de coisa julgada e não ofensa à ordem pública.

Uma questão interessante se refere ao pedido de citação da parte, eis que embora seja um ato possível através do auxilio direto, é necessária a delibação

7 SOARES, Boni de Moraes. "Um réquiem ao velho juízo de delibação: homenagem póstuma à tradicional cognição no direito processual internacional brasileiro" in CARVALHO RAMOS, André de e MENEZES, Wagner. Direito Internacional Privado e a nova cooperação jurídica internacional. Belo Horizonte: Fórum, 2014, p. 59.

${ }^{8}$ Novo Código de Processo Civil brasileiro. Lei 13.105 de 16 de março de 2015.

http://revistasapereaude.org/index.php/edicoes/ano-5-volume-4-novembro-2016

D.O.I: $10.20523 /$ sapereaude-ano5-vol-4-pg-19-39 
quanto aos pressupostos processuais da ação, devendo passar pela admissibilidade.

Na nova era dos direitos humanos, a jurisdição internacional deveria ser una e de fácil acesso às justiças estrangeiras.

O conceito de jurisdição sempre esteve vinculado a seus próprios limites territoriais, mas se percebe que cabe ao direito internacional privado, com seu arsenal teórico-prático resolver esse conflito e diminuir as barreiras entre as soberanias, contribuindo para a viabilidade e o equilíbrio das relações privadas internacionais ${ }^{9}$. Assim, incumbe à cada Estado definir a viabilidade (efetividade e conveniência) de critérios para o reconhecimento dos atos jurisdicionais.

A jurisdição é o pressuposto subjetivo da existência de um processo; a competência é o pressuposto subjetivo-objetivo de sua validade, "competência é medida da jurisdição"10.

No art. 23 do NCPC é estabelecida a Jurisdição exclusiva da Justiça brasileira, excluindo qualquer outra. A litispendência internacional (concomitância de demandas idênticas perante o Judiciário brasileiro e estrangeiro) é admitida no processo civil brasileiro, salvo existência de tratados internacionais que especificar de forma diferente.

Estas e outras questões serão abordadas a seguir, sob a perspectiva do tratamento dado à cooperação jurídica internacional pelo Novo Código de Processo Civil.

\section{A COOPERAÇÃO JURÍDICA INTERNACIONAL NO NOVO CÓDIGO DE PROCESSO CIVIL}

Atualmente, as fontes para compreender a cooperação jurídica estrangeira encontra-se compilada no NCPC, dos artigos 26 a 41, e outros, o que trouxe segurança jurídica àqueles que fazem uso do instituto.

\footnotetext{
${ }^{9}$ HUCK, Hermes Marcelo. Sentença estrangeira e lex mercatoria. São Paulo: Saraiva, 1994, p. 4. 10 HUCK, Hermes Marcelo. Sentença estrangeira e lex mercatoria. São Paulo: Saraiva, 1994, p. 5.
} 
Assim, no artigo 26 destacou que a cooperação jurídica internacional será regida pelos tratados aos quais o Brasil aderiu e tratou dos princípios que guiam o instituto, com menção para o papel da autoridade central; no artigo 27 estabeleceu os objetos; os artigos 28 a 34 regulamentou o uso do auxílio direto e a carta rogatória nos artigos 36 e 37; abordou a homologação de sentença estrangeira nos artigos 960 a 965; dos artigos 38 a 41 tratou das questões relativas à cooperação ativa, a transmissão dos pedidos pela autoridade central e a tradução dos documentos; destaca-se também, a exceção da cooperação internacional pela ofensa à ordem pública.

Estas e outras questões serão abordadas a seguir.

\subsection{DOS LIMITES DA JURISDIÇÃO NACIONAL E DA COOPERAÇÃO JURÍDICA INTERNACIONAL}

É importante observar que o NCPC trouxe diversas alterações ao tratamento dado pelo Estado brasileiro à cooperação jurídica internacional. O diploma normativo em questão tratou, nos artigos de 21 a 25 , os limites da jurisdição nacional.

O que se observa é que a lei brasileira não nega a existência de processo perante órgãos jurisdicionais estrangeiros envolvendo as mesmas partes, com 0 mesmo pedido e mesma causa de pedir. A litispendência e/ou a coisa julgada, nestes casos, pressupõe a homologação da decisão estrangeira para surtir no Brasil seus efeitos.

O NCPC estabelece, nos artigos $21^{11}$ e $22^{12}$, uma competência concorrente ou relativa, inovando, neste segundo, no que tange às matérias objeto das ações.

${ }^{11}$ Art. 21. Compete à autoridade judiciária brasileira processar e julgar as ações em que: I - o réu,
qualquer que seja a sua nacionalidade, estiver domiciliado no Brasil; II - no Brasil tiver de ser
cumprida a obrigação; III - o fundamento seja fato ocorrido ou ato praticado no Brasil. Parágrafo
único. Para o fim do disposto no inciso I, considera-se domiciliada no Brasil a pessoa jurídica
estrangeira que nele tiver agência, filial ou sucursal.
12 Art. 22. Compete, ainda, à autoridade judiciária brasileira processar e julgar as ações: I - de
alimentos, quando: a) o credor tiver domicílio ou residência no Brasil; b) o réu mantiver vínculos no
Brasil, tais como posse ou propriedade de bens, recebimento de renda ou obtenção de benefícios
econômicos; II - decorrentes de relações de consumo, quando o consumidor tiver domicílio ou
26 http://revistasapereaude.org/index.php/edicoes/ano-5-volume-4-novembro-2016

D.O.I: 10.20523/sapereaude-ano5-vol-4-pg-19-39 
Além disso, o inciso III do artigo 22 também reconhece a cláusula de eleição de foro. Importante notar até que ponto o ajuste entre as partes, (mesmo que celebrado sob as vestes de negócio processual), pode querer definir o juízo competente ${ }^{13}$.

Nota-se, na redação do artigo $23^{14}$, o estabelecimento da competência absoluta da autoridade judiciária brasileira, com exclusão de qualquer outra, para conhecer de ações que envolvam imóveis situados no Brasil. O ordenamento jurídico brasileiro se preocupou com o pagamento de tributos quando se tratar de bem imóvel localizado nos limites do território nacional.

Verifica-se, também, a inovação do inciso III, sobre o divórcio ou dissolução de união estável, pois se se tratar de imóvel a partilhar situado no Brasil, a ação deverá ser proposta perante a justiça brasileira. No caso concreto, caso a ação não seja processada e julgada pela autoridade judiciária brasileira, o Superior Tribunal de Justiça não homologará a sentença estrangeira.

$\mathrm{O}$ artigo $24^{15}$ dispõe que a ação proposta perante tribunal estrangeiro não induz litispendência e não obsta a que a autoridade judiciária brasileira conheça da mesma causa. Em outras palavras, o NCPC não reconhece a litispendência internacional, salvo se existirem tratados internacionais que dispuserem de modo diverso.

residência no Brasil; III - em que as partes, expressa ou tacitamente, se submeterem à jurisdição nacional.

${ }^{13}$ BUENO, Cassio Scarpinella. Novo Código de Processo Civil Anotado. São Paulo: Saraiva, 2015, p. 58.

${ }_{14}$ Art. 23. Compete à autoridade judiciária brasileira, com exclusão de qualquer outra: I - conhecer de ações relativas a imóveis situados no Brasil; II - em matéria de sucessão hereditária, proceder à confirmação de testamento particular e ao inventário e à partilha de bens situados no Brasil, ainda que $o$ autor da herança seja de nacionalidade estrangeira ou tenha domicílio fora do território nacional; III - em divórcio, separação judicial ou dissolução de união estável, proceder à partilha de bens situados no Brasil, ainda que o titular seja de nacionalidade estrangeira ou tenha domicílio fora do território nacional.

${ }^{15}$ Art. 24. A ação proposta perante tribunal estrangeiro não induz litispendência e não obsta a que a autoridade judiciária brasileira conheça da mesma causa e das que lhe são conexas, ressalvadas as disposições em contrário de tratados internacionais e acordos bilaterais em vigor no Brasil. Parágrafo único. A pendência de causa perante a jurisdição brasileira não impede a homologação de sentença judicial estrangeira quando exigida para produzir efeitos no Brasil.

http://revistasapereaude.org/index.php/edicoes/ano-5-volume-4-novembro-2016

D.O.I: 10.20523/sapereaude-ano5-vol-4-pg-19-39 
Já o artigo $25^{16}$ trata da cláusula de eleição de foro exclusivo estrangeiro em contrato internacional. Da mesma forma que 0 art. 22, III, trata da eleição do foro sendo competente a justiça brasileira, o art. 25, trata da exclusão desta. Entretanto, cabe ao réu alegar em contestação a cláusula da eleição de foro, sob pena de ser atribuída à justiça brasileira competência concorrente, ou seja, o autor não deverá ajuizar ação no Brasil, mas pode fazê-lo.

Uma vez analisado o tratamento dado aos limites da jurisdição nacional, a seguir, passa-se à análise do tratamento dado pelo NCPC à cooperação jurídica internacional.

\subsection{A OBSERVAÇÃO DOS TRATADOS E DOS PRINCÍPIOS PARA A COOPERAÇÃO JURÍDICA INTERNACIONAL}

O artigo $26^{17}$ do NCPC, especificamente nos incisos I a $\vee$ estão listados os princípios que guiarão a cooperação jurídica internacional. Tais princípios se encontram no rol dos direitos fundamentais da Constituição Federal do Brasil, e ainda assim se faz necessário reiterá-los tendo em vista o objetivo de efetiva garantia dos mesmos no processo de cooperação.

\footnotetext{
${ }^{16}$ Art. 25. Não compete à autoridade judiciária brasileira o processamento e o julgamento da ação quando houver cláusula de eleição de foro exclusivo estrangeiro em contrato internacional, arguida pelo réu na contestação. $\S 1^{\circ}$ Não se aplica o disposto no caput às hipóteses de competência internacional exclusiva previstas neste Capítulo. $\S 2^{\circ}$ Aplica-se à hipótese do caput o art. $63, \S \S 1^{\circ} \mathrm{a}$ $4^{\circ}$.

17 Art. 26. A cooperação jurídica internacional será regida por tratado de que o Brasil faz parte e observará: I - o respeito às garantias do devido processo legal no Estado requerente; II - a igualdade de tratamento entre nacionais e estrangeiros, residentes ou não no Brasil, em relação ao acesso à justiça e à tramitação dos processos, assegurando-se assistência judiciária aos necessitados; III - a publicidade processual, exceto nas hipóteses de sigilo previstas na legislação brasileira ou na do Estado requerente; IV - a existência de autoridade central para recepção e transmissão dos pedidos de cooperação; V - a espontaneidade na transmissão de informações a autoridades estrangeiras. $\S$ $10 \mathrm{Na}$ ausência de tratado, a cooperação jurídica internacional poderá realizar-se com base em reciprocidade, manifestada por via diplomática. $\S 20$ Não se exigirá a reciprocidade referida no $\S 10$ para homologação de sentença estrangeira. $\S 30 \mathrm{Na}$ cooperação jurídica internacional não será admitida a prática de atos que contrariem ou que produzam resultados incompatíveis com as normas fundamentais que regem o Estado brasileiro. § 40 O Ministério da Justiça exercerá as funções de autoridade central na ausência de designação específica.
}

http://revistasapereaude.org/index.php/edicoes/ano-5-volume-4-novembro-2016

D.O.I: 10.20523/sapereaude-ano5-vol-4-pg-19-39 
Atualmente, as fontes para compreender a cooperação jurídica estrangeira encontra-se compilada no NCPC, tratados internacionais e pela reciprocidade entre os Estados (chamado de Princípio da Reciprocidade).

Já os artigos 26, §1o, $31^{18}$ e $41^{19}$ NCPC, tratam do Princípio da Reciprocidade entendendo que existe a presunção de autenticidade no envio de documentos e/ou informações na comunicação e atos entre as autoridades centrais.

A autoridade central é o órgão responsável pela boa condução da cooperação jurídica internacional. O Ministério da Justiça é quem exerce essa função no Brasil, como determina o $\S 40$ do Art. 26, por meio do Departamento de Recuperação de Ativos e Cooperação jurídica da Secretaria Nacional de Justiça (DRCI/SNJ).

O papel da autoridade central do país de origem é encaminhar os pedidos de cooperação para a autoridade central brasileira, ou vice-versa.

A autoridade central é um conceito aplicado ao Direito Internacional, e visa determinar um centro integrado de contato para a tramitação dos pedidos de cooperação jurídica internacional, objetivando à efetividade e à celeridade dos pedidos vindo de outros Países. Sua função é receber, analisar, adequar, transmitir e acompanhar o cumprimento dos pedidos perante as autoridades estrangeiras ${ }^{20}$.

A regra é que o Ministério da Justiça seja a autoridade central ${ }^{21}$, caso não exista outra específica. No entanto, existem diversos tratados que a autoridade central é o Ministério Público. O papel da autoridade central é fazer uma verdadeira

\footnotetext{
18 Art. 31. A autoridade central brasileira comunicar-se-á diretamente com suas congêneres e, se necessário, com outros órgãos estrangeiros responsáveis pela tramitação e pela execução de pedidos de cooperação enviados e recebidos pelo Estado brasileiro, respeitadas disposições específicas constantes de tratado.

19 Art. 41. Considera-se autêntico o documento que instruir pedido de cooperação jurídica internacional, inclusive tradução para a língua portuguesa, quando encaminhado ao Estado brasileiro por meio de autoridade central ou por via diplomática, dispensando-se ajuramentação, autenticação ou qualquer procedimento de legalização. Parágrafo único. O disposto no caput não impede, quando necessária, a aplicação pelo Estado brasileiro do princípio da reciprocidade de tratamento.

20 BUENO, Cassio Scarpinella. Novo Código de Processo Civil Anotado. São Paulo: Saraiva, 2015, p. 60.

${ }^{21}$ Autoridade Central - Min. da Justiça: pratica ato jurisdicional requerendo ao Judiciário (AGU/MP) para tomarem as providencias; pratica não jurisdicional - por ex. respondendo ao pedido de informação de processo.
}

http://revistasapereaude.org/index.php/edicoes/ano-5-volume-4-novembro-2016

D.O.I: 10.20523/sapereaude-ano5-vol-4-pg-19-39 
"triagem", ou seja, o juízo de admissibilidade do pedido. Portanto, não cabe analisar o mérito do pedido.

Em se tratando de ato meramente administrativo que não envolva ato jurisdicional, a própria autoridade central tomará as providências, por via diplomática. No caso brasileiro, através do Itamaraty.

O §3o do art. 26 se refere à Recusa da Cooperação quando existir ofensa à ordem pública, à soberania, às garantias processuais, aos direitos fundamentais, ao devido processo legal. A redação ampla e aberta sugere que o Brasil fara uso do dispositivo para não permitir ou recusar a cooperação jurídica internacional.

Os dados do Departamento de Recuperação de Ativos e Cooperação Internacional, de 2015, apontam que o Brasil é um dos países que mais se utiliza da cooperação como Estado requerente, ao passo que dificulta a cooperação quando é o Estado requerido. Segundo Nádia de Araújo, foram 2469 pedidos ativos contra 788 pedidos passivos na área de cooperação cível ${ }^{22}$.

É importante lembrar que a espontaneidade na transmissão de informações significa evitar a coação, a fraude, às vezes, os movimentos políticos, etc. Trata-se da manifestação de liberdade para a produção do ato.

\subsection{PROCEDIMENTOS E MECANISMOS DA COOPERAÇÃO JURÍDICA INTERNACIONAL E O NOVO CÓDIGO DE PROCESSO CIVIL}

Dentro da análise dos procedimentos da cooperação, é possível classificá-los em procedimento administrativo e jurisdicional.

O Procedimento administrativo é feito pelo Poder Executivo e não necessita de prestação jurisdicional. A Autoridade Central adotará as medidas para seu cumprimento (art. 32), como por exemplo, conhecer e transmitir o andamento de processo.

\footnotetext{
22 ARAUJO, Nádia de. Direito Internacional Privado: Teoria e Prática Brasileira. Porto Alegre: Revolução eBook, 2016, p. 151.
}

http://revistasapereaude.org/index.php/edicoes/ano-5-volume-4-novembro-2016 
Já o Poder Judiciário atua no procedimento jurisdicional, conforme se lê no art. $27^{23}$ do NCPC e para tanto, no requerimento do ato, exige-se capacidade postulatória.

Como mecanismo de cooperação internacional, o NCPC traz em seu bojo o chamado o auxílio direto, a carta rogatória e a ação de homologação de sentença estrangeira.

Por meio do auxilio direto, o Estado requerente solicita que outro Estado estrangeiro profira um ato jurisdicional que pode refletir em provimento administrativo, via autoridade central ou puramente judicial.

$\mathrm{O}$ art. $28^{24}$ do NCPC dispõe que caberá auxílio direto quando a medida não decorrer diretamente de decisão de autoridade jurisdicional estrangeira a ser submetida a juízo de delibação no Brasil, ou seja, a comunicação é feita diretamente, sem passar pelo Poder Judiciário.

Consta desse artigo que não compreende ato jurisdicional estrangeiro, mas apenas a solicitação ao Estado requerido para que, sendo possível, profira e cumpra tal ato. Pode-se ilustrar como exemplo, em vez de o Estado proferir 0 ato, decretando busca e apreensão, encaminha para o Brasil realizar e cumprir.

Diferentemente da carta rogatória e da homologação em que o País requerido não pratica ato jurisdicional de mérito, apenas faz um mero juízo de "delibação" para cumprir o que o País de origem solicita.

No auxilio direto não há juízo de delibação pelo STJ, o que ocorre é o cumprimento pela autoridade central ou requerimento ao Judiciário para a realização do ato.

${ }^{23}$ Art. 27. A cooperação jurídica internacional terá por objeto: I - citação, intimação e notificação judicial e extrajudicial; II - colheita de provas e obtenção de informações; III - homologação e cumprimento de decisão; IV - concessão de medida judicial de urgência; V - assistência jurídica internacional;

${ }^{24}$ Art. 28. Cabe auxílio direto quando a medida não decorrer diretamente de decisão de autoridade jurisdicional estrangeira a ser submetida a juízo de delibação no Brasil.

http://revistasapereaude.org/index.php/edicoes/ano-5-volume-4-novembro-2016

D.O.I: 10.20523/sapereaude-ano5-vol-4-pg-19-39 
Na sequência, o art. $29^{25}$ do NCPC determina que a solicitação de auxílio direto será encaminhada pelo órgão estrangeiro interessado à autoridade central, cabendo ao Estado requerente assegurar a autenticidade e a clareza do pedido, ou seja, todo pedido feito por Estado estrangeiro deve ser encaminhado à autoridade central, como centro unificado para direcionar os atos judiciais ou administrativos.

O auxilio direto terá os seguintes objetos, além dos previstos em tratados internacionais, previsão constante no art. $30^{26}$ : a) comunicação de atos processuais (intimação, citação e notificação); b) obtenção e prestação de informações, salvo segredo de justiça; c) colheita de provas (que é necessariamente jurisdicional, sendo enviado à autoridade central que, por meio do Advogado Geral da União ou do membro do Ministério Público, solicitará a colheita de provas, ocasião em que o ato é praticado dentro do território brasileiro).

Importante anotar que a citação será por carta rogatória quando tenha que passar por juízo de delibação.

Já no artigo $31^{27}$ do NCPC consta que a autoridade central brasileira comunicar-se-á diretamente com suas congêneres e, se necessário, com outros órgãos estrangeiros responsáveis pela tramitação e pela execução de pedidos de cooperação enviados e recebidos pelo Estado brasileiro, respeitadas disposições específicas constantes de tratado.

Isso se justifica por prever que a autoridade central brasileira (que atualmente é o Departamento de Recuperação de Ativos e Cooperação Jurídica Internacional (DRCl), da Secretaria Nacional de Justiça, do Ministério da Justiça) irá se comunicar diretamente com as autoridades centrais de outros países, e se for o caso com

\footnotetext{
${ }^{25}$ Art. 29. A solicitação de auxílio direto será encaminhada pelo órgão estrangeiro interessado à autoridade central, cabendo ao Estado requerente assegurar a autenticidade e a clareza do pedido. ${ }^{26}$ Art. 30. Além dos casos previstos em tratados de que o Brasil faz parte, o auxílio direto terá os seguintes objetos: I - obtenção e prestação de informações sobre o ordenamento jurídico e sobre processos administrativos ou jurisdicionais findos ou em curso; II - colheita de provas, salvo se a medida for adotada em processo, em curso no estrangeiro, de competência exclusiva de autoridade judiciária brasileira; III - qualquer outra medida judicial ou extrajudicial não proibida pela lei brasileira.

${ }_{27}$ Art. 31. A autoridade central brasileira comunicar-se-á diretamente com suas congêneres e, se necessário, com outros órgãos estrangeiros responsáveis pela tramitação e pela execução de pedidos de cooperação enviados e recebidos pelo Estado brasileiro, respeitadas disposições específicas constantes de tratado.
} 
órgãos estrangeiros responsáveis pela tramitação e execução de pedidos de cooperação em que o Brasil seja requerente ou requerido.

Apesar de um avanço considerado pequeno sob a ótica dos internacionalistas, não se pode deixar de considerar que a regulamentação da cooperação jurídica, integrando o direto processual civil brasileiro, terá melhores condições de garantir segurança e a estabilidade para as relações internacionais.

\subsection{CARTA ROGATÓRIA E AÇÃO DE HOMOLOGAÇÃO DE SENTENÇA ESTRANGEIRA}

Por fim, o art. $36^{28}$ NCPC trata da carta Rogatória com competência ao STJ fazer o juízo de delibação. O §10 se refere a "atendimento aos requisitos", o que significa atender ao despacho ou decisão estrangeira sem, contudo, revisar o mérito. Uma vez, concedido o exequatur (autorização) encaminha-se ao Juiz Federal local para cumprimento da decisão.

O Brasil aceita a jurisdição estrangeira no que se refere à competência concorrente, como anteriormente delineado. Qualquer sentença, salvo as de competência exclusiva da justiça brasileira poderá ser homologada pelo STJ. Portanto, não será homologada sentença estrangeira e, tampouco, concedida ordem de exequatur se a jurisdição brasileira for exclusiva (artigos 964 e 965 do NCPC).

O NCPC dispõe no artigo $963^{29}$ sobre os requisitos formais para a homologação da decisão estrangeira.

\footnotetext{
${ }^{28}$ Art. 36 O procedimento da carta rogatória perante o Superior Tribunal de Justiça é de jurisdição contenciosa e deve assegurar às partes as garantias do devido processo legal. $\S 10 \mathrm{~A}$ defesa restringir-se-á à discussão quanto ao atendimento dos requisitos para que o pronunciamento judicial estrangeiro produza efeitos no Brasil. § 20 Em qualquer hipótese, é vedada a revisão do mérito do pronunciamento judicial estrangeiro pela autoridade judiciária brasileira.

${ }^{29}$ Art. 963. Constituem requisitos indispensáveis à homologação da decisão: I - ser proferida por autoridade competente; II - ser precedida de citação regular, ainda que verificada a revelia; III - ser eficaz no país em que foi proferida; IV - não ofender a coisa julgada brasileira; V - estar acompanhada de tradução oficial, salvo disposição que a dispense prevista em tratado; VI - não conter manifesta ofensa à ordem pública.
}

http://revistasapereaude.org/index.php/edicoes/ano-5-volume-4-novembro-2016

D.O.I: 10.20523/sapereaude-ano5-vol-4-pg-19-39 
Por fim, como requisito material, as leis, atos e sentenças de outro país, bem como quaisquer declarações de vontade, não terão eficácia no Brasil, quando ofenderem a soberania nacional, a ordem pública e os bons costumes.

A homologação de sentença estrangeira consiste em ato de reconhecimento de decisão/julgado estrangeiro, com o objetivo de que este produza efeitos em outro território nacional.

Esse mecanismo de aplicação da cooperação jurídica internacional reflete o respeito ao princípio da soberania dos Estados. Entretanto, para se efetivar a justiça universal é necessário se flexibilizar a soberania e para que o Estado atue como Estado requerente e requerido nos pedidos de cooperação.

O reconhecimento e a execução de sentença estrangeira têm significados diferentes. O reconhecimento implica em aceitação ao passo que a execução será a consequência do pedido ao Juiz, possuindo efeitos de uma sentença judicial com possibilidade a extensão no foro.

Por exemplo, a citação e a verificação de suas circunstâncias, bem como a consequente eventual revelia e, particularmente, sua caracterização, são vistas como matéria de ordem pública pela maioria das legislações do mundo.

Importante mecanismo criado é o auxilio direto, que através da autoridade central poderá efetivar a citação da pessoa, como anteriormente explanado.

Os elementos que compõem o juízo de delibação giram em torno da preservação de princípios gerais do ordenamento jurídico em que se pretende executar 0 ato jurisdicional, sem que haja análise de fundo.

Delibação é examinar, experimentar, tocando de leve apenas seus requisitos externos, examinando sua legitimidade, sem entrar a fundo, ou mérito do julgado ${ }^{30}$.

Entretanto, ainda que não seja feita a análise de mérito, há observância de formalidades externas, tais como: competência do juiz internacional, observância do contraditório, trânsito em julgado e não ofensa à ordem pública. 30 BUENO, Cassio Scarpinella. Novo Código de Processo Civil Anotado. São Paulo: Saraiva, 2015, p.
64.

http://revistasapereaude.org/index.php/edicoes/ano-5-volume-4-novembro-2016

D.O.I: 10.20523/sapereaude-ano5-vol-4-pg-19-39 
No que tange a esta, necessário se faz estabelecer a diferença de ordem pública interna e ordem pública internacional. A identificação da ordem pública interna é a existência de uma Constituição como norma suprema nos limites do território do Estado. Já o conceito de ordem pública internacional está ligado à preservação dos valores, das regras do direito interno e sua aplicação. Os princípios gerais do direito internacional (princípio da soberania) e o reconhecimento dos direitos humanos como valor universal incorporado pela ordem pública de cada País.

Por fim, é necessário reconhecer que a ordem publica interna serve para garantir a aplicabilidade e eficácia das normas imperativas. Por outro lado, no direito internacional, a ordem pública vai se caracterizar como limite à aplicação do direito estrangeiro.

\section{COOPERAÇÃO JURÍDICA INTERNACIONAL E A GARANTIA DOS DIREITOS HUMANOS}

A expressão 'acesso internacional à justiça' é visto como o requisito fundamental (requisito básico dos direitos humanos), para a construção de um sistema jurídico igualitário que proteja os direitos de todas as pessoas ${ }^{31}$.

Sobre o tema, Peter Haberle já explanou que:

A resposta à questão sobre o conteúdo essencial dos direitos fundamentais exige uma determinação do sentido dos mesmos no seu conjunto da Constituição; reclama a inserção dos direitos fundamentais - e da determinação de sua função - neste conjunto; é necessário esclarecer as relações de tais direitos com outros bens jurídicos-constitucionais (tradução livre) ${ }^{32}$.

\footnotetext{
31 Informações exraídas do manual de Cooperação jurídica internacional. BRASIL, Ministério da Justiça. Cooperação Jurídica Internacional. Disponível em: <http://www.justica.gov.br/suaprotecao/cooperacao-internacional>. Acesso em: 20, jul. 2016.

32 "La respuesta a la cuestión sobre el contenido esencial de los derechos fundamentales exige una determinación del sentido de los mismos en el conjunto de la Constitución; reclama la inserción de los derechos fundamentales - y la determinación de su función - en este conjunto; hace necesario aclarar las relaciones de dichos derechos con los otros bienes juridicos-constitucionales" (HARBELE, Peter. La Garantía del contenido esencial de los derechos fundamentales. Madrid, 2003. p.7).
}

http://revistasapereaude.org/index.php/edicoes/ano-5-volume-4-novembro-2016

D.O.I: 10.20523/sapereaude-ano5-vol-4-pg-19-39 
Em razão da crescente mobilidade de pessoas entre os países, os diferentes ordenamentos jurídicos, as barreiras de acesso ao judiciário de outras soberanias ganham importância e geram insegurança no enfrentamento de obstáculos de acesso a sistemas estrangeiros que deveriam ser acessíveis a todos, independentemente de seu domicílio.

Assim, é possível enumerar alguns dos principais obstáculos que surgem no contexto internacional para a acessibilidade dos Judiciários, como por exemplos:

a) exigência por parte de alguns judiciários estrangeiros de pagamento de caução, depósito ou qualquer outro tipo de garantia perante a justiça por ser estrangeiro ou por não ser residente ou domiciliado no território do outro Estado;

b) dificuldade de acesso a um advogado no estrangeiro, seja por desconhecimento de como obter referências seja pelo preço cobrado pelos honorários;

c) dificuldade de obtenção do benefício da justiça gratuita;

d) grande desconhecimento sobre os sistemas jurídicos estrangeiros: se para o leigo o sistema nacional se apresenta como complexo, compreender as diferenças entre sistemas jurídicos distintos demanda enorme, e por vezes infrutífero, esforço ${ }^{33}$.

Atualmente, no Brasil, alguns desses obstáculos, tem sido solucionados pelo papel da autoridade central brasileira, a qual, recebe a solicitação e encaminha ao Estado estrangeiro sem que o indivíduo nacional precise de deslocar até o outro país.

O Ministério da Justiça brasileiro já vem agindo dessa forma, sendo que no ano de 2016 entrou em vigor o NCPC que regulamentou todo o mecanismo de cooperação jurídica internacional.

É necessário, no entanto, superar a ideia de que a soberania de um Estado é absoluta dentro de suas fronteiras, como delineada no Tratado de Westphalia, em 1648. Por certo que a soberania absoluta tem sido relativizada pelos fenômenos da globalização e da internacionalização dos direitos humanos.

\footnotetext{
${ }^{33}$ BRASIL, Ministério da Justiça. Acesso Internacional à Justiça. Disponível em: $<$ http://www.justica.gov.br/sua-protecao/cooperacao-internacional/cooperacao-juridica-internacionalem-materia-civil/acesso-internacional-a-justica>. Acesso em: 20 jul, 2016.
}

http://revistasapereaude.org/index.php/edicoes/ano-5-volume-4-novembro-2016 
É preciso reconhecer que existe uma comunidade humana que ultrapassa as fronteiras dos Estados, e que esta humanidade compartilha de valores comuns que devem ser preservados a todos os seres humanos. A violação desses preceitos significa negar ao ser humano sua própria essência, o que afeta toda a ordem humana ${ }^{34}$.

Nesse sentido, também é imperioso reconhecer que o Estado brasileiro está inserido nesta comunidade internacional e que partilha dos mesmos valores de proteção dos direitos humanos e que a cooperação jurídica internacional deve servir, também, para a efetivação desses direitos.

Com isso, negar o acesso à cooperação jurídica internacional é violar os direitos humanos, na medida em que a globalização e a internacionalização ultrapassam as fronteiras previamente delimitadas pelos Estados.

\section{CONCLUSÃO}

O Direito Internacional Privado é ramo do direito interno que regula as relações privadas internacionais. A tendência é aumentar cada vez mais, em razão da globalização que aproxima pessoas, mercados, etc.

Diante das relações plurilocalizadas, multiconectadas ou atípicas, é necessário que haja cooperação internacional entre os países do globo, mantendo as bases da dignidade da pessoa humana, como valor fundamental no direito interno (países democráticos ou não) e no direito internacional.

Os Estados soberanos possuem suas leis internas e determinam a legislação de direito privado, podendo aplicá-las dentro e/ou fora de se seu território.

O DIPr vem sofrendo forte influência de fontes internacionais, deixando de predominar regras nacionais e limitadas dentro do território de determinado Estado. Destacando-se uma ambição universal da matéria através da elaboração de diversos tratados.

34 DELMAS-MARTY, Mireille. Por um direito comum. Tradução Maria Ermantina de Almeida Prado Galvão. São Paulo: Martins Fontes, 2004, p. 186.

http://revistasapereaude.org/index.php/edicoes/ano-5-volume-4-novembro-2016 
Por isso, a importância de se desenvolver mecanismos de cooperação jurídica em âmbito internacional, para que seja possível o acesso à justiça de todos os indivíduos.

O Processo Civil Internacional brasileiro, embora tímido, caminha a passos lentos para uma cooperação jurídica sem barreiras e, talvez, porque não, ideal.

\section{REFERÊNCIAS BIBLIOGRAFICAS}

ARAUJO, Nádia de. Direito Internacional Privado: Teoria e Prática Brasileira. Porto Alegre: Revolução eBook, 2016,

BRASIL, Ministério da Justiça. Acesso Internacional à Justiça. Disponível em: <http://www.justica.gov.br/sua-protecao/cooperacao-internacional/cooperacaojuridica-internacional-em-materia-civil/acesso-internacional-a-justicas. Acesso em: 20 jul, 2016.

BRASIL, Ministério da Justiça. Cooperação Jurídica Internacional. Disponível em: <http://www.justica.gov.br/sua-protecao/cooperacao-internacional>. Acesso em: 20, jul. 2016.

BUENO, Cassio Scarpinella. Novo Código de Processo Civil Anotado. São Paulo: Saraiva, 2015.

CARVALHO RAMOS, André de. "Direito Internacional Privado e seus aspectos processuais: a cooperação jurídica internacional" in CARVALHO RAMOS, André de e MENEZES, Wagner. Direito Internacional Privado e a nova cooperação jurídica internacional. Belo Horizonte: Forum, 2014.

CASTRO, José Luis Cascajo, La proteccion de los derechos em Latinoamérica desde uns perspectiva comparada, Salamanca, 2013.

DELMAS-MARTY, Mireille. Por um direito comum. Tradução Maria Ermantina de Almeida Prado Galvão. São Paulo: Martins Fontes, 2004.

GIMÉNEZ, Luis María Diez-Picazo, Sistema de Derechos Fundamentales, 4a Ed, Espanha, Thomson Reters, 2013.

HÃBERLE, Peter, La Garantía del contenido esencial de los derechos fundamentales, Madrid, 2003.

http://revistasapereaude.org/index.php/edicoes/ano-5-volume-4-novembro-2016 
HUCK, Hermes Marcelo. Sentença estrangeira e lex mercatoria. São Paulo: Saraiva, 1994.

MAZZUOLI, Valerio de Oliveira, Curso de Direito Internacional Público, 4⿳亠丷. Ed, São Paulo, 2010.

MIRAGEM, Bruno. "Conteúdo da ordem pública e os direitos humanos. Elementos para um direito internacional pós-moderno" in MARQUES, Cláudia Lima e ARAUJO, Nádia de (orgs). O novo direito internacional. Estudos em homenagem a Erik Jayme. Rio de Janeiro: Renovar, 2005, pp. 307-354.

PIOVESAN, Flavia, Direitos Humanos e o Direito Constitucional Internacional, 10 Ed, São Paulo: Saraiva, 2009.

SOARES, Boni de Moraes. "Um réquiem ao velho juízo de delibação: homenagem póstuma à tradicional cognição no direito processual internacional brasileiro" in CARVALHO RAMOS, André de e MENEZES, Wagner. Direito Internacional Privado e a nova cooperação jurídica internacional. Belo Horizonte: Fórum, 2014, pp. 53-78.

TRINDADE, Antonio Augusto Cançado, Tratado de Direito Internacional dos Direitos Humanos, volume 1, 1를.

WANBIER, Teresa Arruda Alvin e WAMBIER, Luiz Rodrigues. Código de Processo Civil Comparado. Artigopor artigo. São Paulo. Revista dos Tribunais, pp39 a 44 e 451 a 453.

http://www.justica.gov.br/sua-protecao/cooperacao-internacional

http://revistasapereaude.org/index.php/edicoes/ano-5-volume-4-novembro-2016

D.O.I: 10.20523/sapereaude-ano5-vol-4-pg-19-39 